Original Article

\title{
The Relationship Between HbA1c and Contrast-Induced Nephropathy in Patients with Non-ST Elevation Myocardial Infarction and Non-Established Diabetes Mellitus
}

Onur BAYDAR ${ }^{1}$ (D)

${ }^{1}$ Department of Cardiology, Avicenna Hospital, Istanbul, Turkey

\section{A B S T R A C T}

Background Diabetes Mellitus (DM) is an important cardiovascular risk factor and 50\% of newly diagnosed diabetic patients have coronary artery disease. HbA1c levels in these patients have an effect on prognosis. Development of contrast agent-induced nephropathy (CIN) is common in patients who have undergone percutaneous coronary intervention (PCI) without ST elevation myocardial infarction (NSTEMI) and is associated with increased mortality and morbidity. In this study, the relationship between $\mathrm{HbA} 1 \mathrm{c}$ and the development of CIN was investigated in NSTEMI patients who did not have a previous diagnosis of DM and receive treatment.

Material and Methods In this study, 359 (189, 52.6\% male) patients who were not diagnosed with DM and did not receive treatment were retrospectively analyzed for NSTEMI diagnosis. HbA1c and creatinine values before and after the procedure were evaluated. CIN was defined as an increase of $25 \%$ or $0.5 \mathrm{mg}$ / $\mathrm{dL}$ compared to the basal value in serum creatinine measured 48-72 hours after the procedure.

Results CIN was detected in 56(15.6\%) of all patients. Among the group with and without CIN; There was no difference between gender, amount of contrast material, pre-procedure eGFR, troponin and ejection fraction values. Only in the group with $\mathrm{CIN}$, the patients were older and the number of hypertensive patients was significantly higher. As a result of coronary angiography, medical follow-up was made for $46(12.7 \%)$ patients, coronary stent in $271(74.7 \%)$ and coronary bypass in $40(11 \%)$ patients. In addition, in-hospital mortality was detected in 17 (4.7\%) patients. HbA1c and fasting glucose levels were found significantly higher in the group developing CIN $(6.1 \pm 1.0$ vs. $5.5 \pm 0.6 \mathrm{mg} / \mathrm{dL}, \mathrm{p}<0.001$, $133.8 \pm 65.9$ vs. $110.9 \pm 48.7 \mathrm{mg} / \mathrm{dL}, \mathrm{p}=0.002$, respectively). But only the $\mathrm{HbA} 1 \mathrm{c}$ value was determined to be an independent predictor in the logistic regression analysis of CIN (OR: 2.3, p<0.001, CI: 1.6-3.2). Conclusions CIN was more common in NSTEMI patients with high HbA1c who were not diagnosed with $\mathrm{DM}$ and were not treated. In addition, $\mathrm{HbA1c}$ value was an independent predictor of $\mathrm{CIN}$ development.

Turk J Int Med 2021;3(4):172-176

DOI: $\underline{10.46310 / \text { tjim. } 882755}$

Keywords: HbA1c, nephropathy, myocardial infarction.

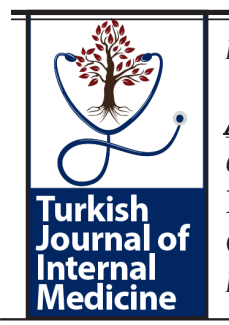

Received: February 18,2021;Accepted:May 23,2021; Published Online:October 29,2021 


\section{Introduction}

Percutaneous coronary intervention (PCI) in patients with non-ST-elevation myocardial infarction (NSTEMI) reduces ischemic complications and improves survival. Patients undergoing PCI are at high risk for contrast-induced nephropathy (CIN) and this has been associated with renal dysfunction, longer hospital stay, increased cardiovascular events and mortality. ${ }^{1,2}$ So many factors such as hypovolemia, contrast volume, and baseline glomerular filtration rate (GFR) may contribute to the development of CIN. ${ }^{3,4}$ Because of this, identifying patients at risk of CIN is important in patients undergoing PCI. Diabetes Mellitus (DM) is an important cardiovascular risk factor and $50 \%$ of newly diagnosed diabetic patients have coronary artery disease. HbA1c levels in these patients have an effect on prognosis. A recent study indicated that elevated $\mathrm{HbA} 1 \mathrm{c}$ is an independent factor associated with CIN among patients without diabetes undergoing elective coronary angiography or PCI. ${ }^{5}$ But there was not enough information in patients with NSTEMI. Therefore, in this study aimed to examine the effects of elevated $\mathrm{HbAlc}$ on CIN after coronary angiography in NSTEMI patients who did not have a previous diagnosis of $\mathrm{DM}$ and did not receive treatment.

\section{Material and Methods}

The study prospectively observed 359 consecutive patients with NSTEMI undergoing coronary angiography at the Avicenna Hospital Cardiology Depratment between January 2015 and January 2018. NSTEMI was defined according to the current guidelines. ${ }^{6}$ Patients with severe valvular heart disease, severe or decompensated heart failure, need intra-aortic balloon pressure support, severe renal failure, and patients undergoing emergency cardiac surgery for revascularization, previously diagnosed with DM, and treated for DM (such as metformin, insulin etc.) were excluded. The study was approved by the Local Ethics Committee. In all patients, plasma glucose and Hbalc levels were assessed at hospital admission. Hypertension (HT) was defined as blood pressure $>140 / 90 \mathrm{mmHg}$ or being on treatment with antihypertensive medications. Also, diabetes mellitus (DM) was defined as fasting glucose levels $>126 \mathrm{mg} / \mathrm{dL}$ or being on treatment with oral antidiabetic drugs or insulin.
Finally, hyperlipidemia (HL) was defined by reference to current guidelines. ${ }^{7}$ Serum creatinine concentration level was observed at hospital admission, every day for the following days and at hospital discharge. Estimated GFR (eGFR) was calculated using the modified formula of Levey et al. ${ }^{8}$ CIN was defined as an increase in creatinine $25 \%$ or $0.5 \mathrm{mg} / \mathrm{dL}$ from the baseline value within the 48- 72-hour period following PCI. ${ }^{9}$

\section{Statistical Analysis}

All analyses were performed using SPSS version 22 for Windows (SPSS Inc, Chicago, Illinois). Numerical variables are presented as mean (standard deviation) (SD) and nominals as percentages. All variables were subjected to Kolmogorov Smirnov testing to determine whether they were normally distributed. The independent samples $t$ test was used to compare the values of continuous variables between the 2 groups. Nonparametric values were compared using the Mann-Whitney $U$ test. The chi-square test was used to compare categorical data. To evaluate the effects of various factors on CIN development, we performed multivariate regression analyses using the backward logistic regression (LR) method. Variables for which the unadjusted $\mathrm{P}$ was $<0.05$ was considered significant.

\section{Results}

CIN was detected in $56(15.6 \%)$ of all patients. Among the group with and without CIN; There was no difference between gender, amount of contrast material, pre-procedure eGFR, troponin and ejection fraction values. Only in the group with CIN, the patients were older and the number of hypertensive patients was significantly higher (Table 1). As a result of coronary angiography, medical follow-up was made for $46(12.7 \%)$ patients, coronary stent in $271(74.7 \%)$ and coronary bypass in $40(11 \%)$ patients. Table 2 describes the medications of the cohort. In addition, in-hospital mortality was detected in 17 (4.7\%) patients. HbAlc and fasting glucose levels were found significantly higher in the group developing CIN $(6.1 \pm 1.0$ vs. $5.5 \pm 0.6 \mathrm{mg} / \mathrm{dL}, \mathrm{p}<0.001,133.8 \pm 65.9$ vs. $110.9 \pm 48.7 \mathrm{mg} / \mathrm{dL}, \mathrm{p}: 0.002$, respectively). But only the HbAlc value was determined to be an independent predictor in the logistic regression analysis of CIN (OR: 2.3, p<0.001, CI: 1.6-3.2) (Table 3). 


\section{Discussion}

CIN is a frequent complication after invasive treatment of NSTEMI, even in patients with normal baseline renal function. ${ }^{10}$ It is associated with increased in-hospital mortality and a prolonged hospitalization. Diabetic patients have twice the risk of cardiovascular events of that of healthy individuals. Cardiovascular disease is the leading cause of mortality in diabetic patients, accounting for $75 \%$ of mortalities. ${ }^{11-13}$ In diabetes patients with cardiovascular disease who required coronary angiography or percutaneous coronary intervention, diabetes is a risk factor for acute renal injury after coronary angiography. ${ }^{14}$ $\mathrm{HbAlc}$ is a product of $\mathrm{Hb}$ and blood glucose. It more accurately reflects long-term glycaemic control with blood glucose and helps to identify undiagnosed diabetic patients. ${ }^{15}$ Moreover, chronic hyperglycemia associated with several adverse effects that endothelial dysfunction, increased cytokine activation, increased oxidative stress, impaired microcirculatory function and prothrombotic effects. ${ }^{16-18}$ A study by Barbieri et al. ${ }^{5}$ indicated that among patients without diabetes undergoing elective coronary angiography or PCI, elevated HbA1c but not glucose levels is a factor independently associated with CIN. Similar to these results, our study suggested that HbA1c and fasting glucose levels were significantly higher in the CIN group and only HBA1c is an independent predictor of CIN in NSTEMI patients. As diabetes is one of the most important risk factor for the development of CIN, this observation reinforced our findings and supports the importance of a correct management of this high risk subgroup of patients. On the other side, no relationship was found between fasting glycaemia and the occurrence of CIN.

Contrast volume is an important risk factor for

Table 1. Main characteristics of patients.

\begin{tabular}{llll}
\hline & Patients with CIN & Patients without CIN & p value \\
& \multicolumn{1}{c}{ n: $56(15.6 \%)$} & $\mathrm{n}: 303(84.4 \%)$ & \\
\hline Age (years) & $62.6 \pm 13.3$ & $56.1 \pm 10.2$ & $<0.001$ \\
Male (n\%) & $31(55.4 \&)$ & $158(52.1 \%)$ & 0.65 \\
Weight (kg) & $76.0 \pm 4.4$ & $75.8 \pm 5.9$ & 0.86 \\
HT (n\%) & $41(73.2 \%)$ & $177(58.4 \%)$ & 0.037 \\
HL (n\%) & $23(41.1 \%)$ & $106(35 \%)$ & 0.38 \\
Smoke (n\%) & $14(25 \%)$ & $87(28.7 \%)$ & 0.57 \\
Contrast volume (mL) & $228.3 \pm 15.5$ & $228.6 \pm 17.4$ & 0.91 \\
Previous CABG (n\%) & $8(27.4 \%)$ & $83(14.3 \%)$ & 0.038 \\
Creatinine (mg/dL) & $1.1 \pm 0.1$ & $1.0 \pm 0.08$ & $<0.001$ \\
Peak troponin T level (ng/dL) & $2.2 \pm 0.8$ & $2.2 \pm 0.9$ & 0.94 \\
EF (n\%) & $53.2 \pm 7.4$ & $53.9 \pm 7.7$ & 0.52 \\
eGFR (mL/min/1.73m $\left.{ }^{2}\right)$ & $86.5 \pm 22.7$ & $89.6 \pm 15.1$ & 0.21 \\
HbA1c (\%) & $6.1 \pm 1.0$ & $5.5 \pm 0.6$ & $<0.001$ \\
Fasting glucose (mg/ dL) & $133.8 \pm 65.9$ & $110.9 \pm 48.7$ & 0.002 \\
\hline HThp & & & \\
\hline
\end{tabular}

HT: hypertension, HL: hyperlipidemia, CABG: coronary artery bypass grefting, EF: ejection fraction, GFR: glomerular filtration rate. 
Table 2. Medications taken before the catheterization.

\begin{tabular}{ll}
\hline Medications & $\mathrm{n}(\%)$ \\
\hline Aspirin (n\%) & $170(46.8 \%)$ \\
Clopidogrel (n\%) & $29(8 \%)$ \\
Statins (n\%) & $122(33.6 \%)$ \\
ACE-i/ARB (n\%) & $192(52.9 \%)$ \\
Beta- Blockers (n\%) & $133(36.6 \%)$ \\
CCB (n\%) & $38(10.5 \%)$ \\
Nitrates (n\%) & $60(16.5 \%)$ \\
\hline
\end{tabular}

ACE-i: angiotensin converting enzyme inhibitors, ARB: angiotensin receptor blocker, CCB: calcium channel blocker.

Table 3. Independent risk factors of CIN in logistic regression analysis.

\begin{tabular}{lll}
\hline Variables & OR $(95 \%$ C.I $)$ & p value \\
\hline Weigth & $0.99(0.93-1.0)$ & 0,80 \\
Gender & $1.2(0.6-2.3)$ & 0.54 \\
Age & $1.1(0.7-1.5)$ & 0,57 \\
Fasting glucose & $1,0(0.99-1,0)$ & 0,79 \\
Hypertension & $1.2(0.5-2.6)$ & 0.56 \\
eGFR & $0.99(0.97-1,0)$ & 0,96 \\
HbA1c & $2.3(1.6-3.2)$ & $<0.001$ \\
\hline
\end{tabular}

GFR: glomerular filtration rate.

CIN and dose minimization, on the background of a known baseline reduced renal function, may serve as an important strategy to limit the incidence of CIN. ${ }^{16}$ We used higher contrast level that used during angiography than literature in our patients, we think that it is due to the high rate of patients undergoing PCI (74.7\%). However, we did not find significant difference in terms of dose of contrast used in patients with and without CIN.

The present study supports the relationship between high HbA1c levels and the risk of acute renal dysfunction without established DM. This observation shows the importance the chronic elevation, as a predisposing factor for CIN. This findings should be investigated in future studies.

\section{Conclusions}

CIN was more common in NSTEMI patients with high $\mathrm{HbA} 1 \mathrm{c}$ who were not diagnosed with $\mathrm{DM}$ and were not treated.In addition, HbAlc value was an independent predictor of CIN development.

\section{Conflict of interest}

The author declared that there are no potential conflicts of interest with respect to the research, authorship, and/or publication of this article. 


\section{Authors' Contribution}

Study Conception, Study Design, Supervision, Materials, Data Collection and/or Processing, Statistical Analysis and/or Data Interpretation, Literature Review, Manuscript Preparation, and Critical Review: OB.

\section{References}

1. Keeley EC, Boura JA, Grines CL. Primary angioplasty versus intravenous thrombolytic therapy for acute myocardial infarction: a quantitative review of 23 randomised trials. Lancet 2003;361:13-20. doi: 10.1016/ S0140-6736(03)12113-7.

2. Marenzi G, Lauri G, Assanelli E, Campodonico J, De Metrio M, Marana I, Grazi M, Veglia F, Bartorelli AL. Contrast-induced nephropathy in patients undergoing primary angioplasty for acute myocardial infarction. J Am Coll Cardiol. 2004 Nov 2;44(9):1780-5. doi: 10.1016/j. jacc.2004.07.043.

3. Ishihara M, Inoue I, Kawagoe T, Shimatani Y, Kurisu S, Nishioka K, Umemura T, Nakamura S, Yoshida M. Impact of acute hyperglycemia on left ventricular function after reperfusion therapy in patients with a first anterior wall acute myocardial infarction. Am Heart J. 2003 Oct;146(4):674-8. doi: 10.1016/S0002-8703(03)00167-4.

4. Nakamura T, Ako J, Kadowaki T, Funayama H, Sugawara Y, Kubo N, Momomura S. Impact of acute hyperglycemia during primary stent implantation in patients with ST-elevation myocardial infarction. J Cardiol. 2009 Apr;53(2):272-7. doi: 10.1016/j.jjcc.2008.11.011.

5. Barbieri L, Verdoia M, Schaffer A, Cassetti E, Di Giovine G, Marino P, Suryapranata H, De Lu-ca G. Prediabetes and the risk of contrast induced nephropathy in patients undergoing co-ronary angiography or percutaneous intervention. Diabetes Res Clin Pract. 2014 Dec;106(3):458-64. doi: 10.1016/j.diabres.2014.09.041.

6. Hamm CW, Bassand JP, Agewall S, Bax J, Boersma E, Bueno H, Caso P, Dudek D, Gielen S, Huber K, Ohman M, Petrie MC, Sonntag F, Uva MS, Storey RF, Wijns W, Zahger D; ESC Committee for Practice Guidelines. ESC Guidelines for the management of acute coronary syndromes in patients presenting without persistent STsegment elevation: The Task Force for the management of acute coronary syndromes (ACS) in patients presenting without persistent ST-segment elevation of the European Society of Cardiology (ESC). Eur Heart J. 2011 Dec;32(23):2999-3054. doi: 10.1093/eurheartj/ehr236.

7. Expert Panel on Detection Evaluation, and Treatment of High Blood Cholesterol in Adults. Executive summary of the third report of the National Cholesterol Education Program (NCEP) expert panel on detection, evaluation, and treatment of high blood cholesterol in adults (adult treatment panel III). JAMA. 2001;285(19):2486-97. doi: 10.1001/jama.285.19.2486.

8. Levey AS, Beto JA, Coronado BE, Eknoyan G, Foley RN, Kasiske BL, Klag MJ, Mailloux LU, Manske CL, Meyer KB, Parfrey PS, Pfeffer MA, Wenger NK, Wilson PW, Wright JT Jr. Controlling the epidemic of cardiovascular disease in chronic renal disease: what do we know? What do we need to learn? Where do we go from here? National Kidney Foundation Task Force on Cardiovascular Disease. Am J Kidney Dis. 1998 Nov;32(5):853-906. doi: 10.1016/s0272-6386(98)70145-3.

9. Thomsen HS. European Society of Urogenital Radiology (ESUR) guidelines on the safe use of iodinated contrast media. Eur J Radiol. 2006;60(3):307-13. doi: 10.1016/j. ejrad.2006.06.020.

10. Tepel M, Aspelin P, Lameire N. Contrast-induced nephropathy: a clinical and evidence-based approach. Circulation. 2006 Apr 11;113(14):1799-806. doi: 10.1161/ CIRCULATIONAHA.105.595090.

11. Selvin E, Marinopoulos S, Berkenblit G, Rami T, Brancati FL, Powe NR, Golden SH. Meta-analysis: Glycosylated hemoglobin and cardiovascular disease in diabetes mellitus. Ann Intern Med. 2004 Sep 21;141(6):421-31. doi: 10.7326/0003-4819-141-6-200409210-00007.

12. Balkau B, Shipley M, Jarrett RJ, Pyorala K, Pyörälä K, Pyörälä M, Forhan A, Eschwège E. High blood glucose concentration is a risk factor for mortality in middle-aged nondiabetic men. 20-year follow-up in the Whitehall Study, the Paris Prospective Study, and the Helsinki Poli-cemen Study. Diabetes Care. 1998;21:360-367. doi: 10.2337/diacare.21.3.360.

13. Xu Y, Wang L, He J, Bi Y, Li M, Wang T, Wang L, Jiang Y, Dai M, Lu J, Xu M, Li Y, Hu N, Li J, Mi S, Chen CS, Li G, Mu Y, Zhao J, Kong L, Chen J, Lai S, Wang W, Zhao W, Ning G; 2010 China Noncommunicable Disease Surveillance Group. Prevalence and control of diabetes in Chinese adults. JAMA. 2013 Sep 4;310(9):948-59. doi: 10.1001/jama.2013.168118.

14. McCullough PA, Wolyn R, Rocher LL, Levin RN, Oneill WW. Acute renal failure after coronary intervention: Incidence, risk factors, and relationship to mortality. Am J Med. 1997;103:368-375. doi: 10.1016/s00029343(97)00150-2.

15. Goldstein DE, Little RR, Lorenz RA, Malone JI, Nathan DM, Peterson CM; American Diabetes Association. Tests of glycemia in diabetes. Diabetes Care. 2004 Jan;27 Suppl 1:S91-3. doi: 10.2337/diacare.27.2007.s91.

16. Yang Z, Laubach VE, French BA, Kron IL. Acute hyperglycemia enhances oxidative stress and exacerbates myocardial infarction by activating nicotinamide adenine dinucleotide phosphate oxidase during reperfusion. J Thorac Cardiovasc Surg. 2009 Mar;137(3):723-9. doi: 10.1016/j.jtcvs.2008.08.056.

17. Undas A, Wiek I, Stêpien E, Zmudka K, Tracz W. Hyperglycemia is associated with enhanced thrombin formation, platelet activation, and fibrin clot resistance to lysis in patients with acute coronary syndrome. Diabetes Care. 2008 Aug;31(8):1590-5. doi: 10.2337/dc08-0282.

18. Worthley MI, Holmes AS, Willoughby SR, Kucia AM, Heresztyn T, Stewart S, Chirkov YY, Zeitz CJ, Horowitz JD. The deleterious effects of hyperglycemia on platelet function in diabetic patients with acute coronary syndromes mediation by superoxide production, resolution with intensive insulin administration. J Am Coll Cardiol. 2007 Jan 23;49(3):304-10. doi: 10.1016/j. jacc.2006.08.053. 